\title{
Prevalence of the Different Types of Systemic Arterial Hypertension in Mexican Elderly
}

Lourdes Marcos Ramírez ${ }^{1^{*}}$, Miguel Ángel Mendoza Romo ${ }^{2}$, Francisco Javier López Esqueda ${ }^{3}$, Héctor Gerardo Hernández Rodríguez ${ }^{3}$, Gonzalo Ramón González González ${ }^{4}$, María Cleofás Ramírez Arriola ${ }^{5}$ and Marco Vinicio González Rubio ${ }^{4}$

${ }^{1}$ Medical Intern of Social Service in Medicine, Research and teaching center. Instituto Mexicano del Seguro Social, San Luis Potosí, Mexico

${ }^{2}$ Mexican Social Security Institute, San Luis Potosí Delegation, Mexico

${ }^{3}$ Autonomous University of San Luis Potosí, Mexico

${ }^{4}$ Central Hospital, Ignacio Morones Prieto, San Luis Potosí, Mexico

${ }^{5}$ General Hospital Zone \# 2, Mexican Social Security Institute, San Luis Potosi Delegation, Mexico

*Corresponding author: Dr Lourdes Marcos Ramírez, Medical Trainee, Medical Intern of Social Service in Medicine, Instituto Mexicano del Seguro Social, Research and Teaching Center, Avenida Industrias 105, San Luis Potosí 78399, Mexico, Tel: 00524441518691; E-mail: lulilu898@hotmail.com

Received date: September 27, 2017; Accepted date: October 11, 2017; Published date: October 18, 2017

Copyright: (c) 2017 Ramirez LM, et al. This is an open-access article distributed under the terms of the Creative Commons Attribution License; which permits unrestricted use; distribution; and reproduction in any medium; provided the original author and source are credited.

\section{Abstract}

Objective: To determine the types of presentation of blood pressure figures in elderly hypertensive patients, in the Health, Welfare and Aging survey (SABE) in San Luis Potosí, Mexico.

Materials and methods: Cross-sectional study. Secondary analysis of the group of elderly participants in the multicenter SABE study, who underwent blood pressure measurements.

Results: A total of 1018 women and 805 men were included, with an average age of $71 \pm 8.2$ years. The types of arterial hypertension (HA) present were: isolated systolic hypertension $(35.7 \%)$, isolated diastolic hypertension $(32 \%)$, and systolic-diastolic hypertension (32.3\%). There was no relationship in the distribution of HA with height above sea level. In older adults with diabetes, mean arterial pressure (PAM) was higher.

Discussion: We found that all three types of hypertension maintain balanced percentages of almost one third each, lack of early detection of isolated diastolic hypertension.

Keywords: Older adult; High blood pressure; Diabetes

\section{Introduction}

In Mexico, life expectancy has increased considerably; in 1930 people lived on average 34 years, 40 years later in 1970 this indicator stood at 61 ; in 2000 it was 74 and in 2016 it was 75.2 years. The expectation in San Luis Potosí is 75.5 years and older adults are considered those who are more than 60 years old. According to the projections of the national population council, San Luis Potosí, will reach to have a greater adult population in the 2030 of 472,690, and of this the $18.5 \%$ will be greater of 60 years [1].

In Mexico, the process of demographic aging is not reversible and as a result of this increase, there is also an epidemiological transition, characterized by the persistence of infectious-contagious diseases, as well as by the increase in the number of chronic non-communicable diseases. It is important to emphasize that many of these pathologies begin at earlier stages of life and reach old age, with a series of comorbidities, complications and disabilities. It should be noted that, in developed countries, there is an active and healthy aging [2].

Increased blood pressure (BP) with age and increased longevity, in part, by treatment of chronic diseases, has contributed to an increase in the prevalence of hypertension. This linear and continuous increase in age-related systolic BP occurs in both sexes and is suggested to be a manifestation of both the aging process as well as factors related to lifestyle and genetic predisposition [3].

Untreated Hypertension (HT) can lead to early vascular aging, so the increase in age-related pulse pressure may reflect not only the physiological process, but may also be the consequence of certain processes on additives that produce an aging vascular disease.It represents a disease, as well as an important risk factor for other diseases, mainly ischemic heart disease, heart failure, cerebrovascular disease and renal failure [4].

HT is one of the most prevalent pathologies in the world today, affecting about $25 \%$ of the adult population in developed countries. [5] The elderly represent an increasing public health problem, firstly because life expectancy increases in developed countries and the trend is similar in developing countries, constituting the population group with the highest proportional growth. According to the National Institute of Statistics and Informatics, the population older than 60 years was $6.1 \%$ in $1990,7.1 \%$ in 2000 , estimated at $9.4 \%$ by 2014 and projected at $11.2 \%$ for 2021 [6].

HT is one of the main causes of consultation in primary care. It presents a prevalence that increases with age, affects $68 \%$ of people over 60 years and is slightly higher in women $(70 \%)$ than in men (66\%). The proportion of patients older than 65 years who present with hypertension may be up to $50 \%$. The direct relationship between the increase in systolic (SAD) and diastolic (TAD) blood pressure with 
mortality from stroke and coronary heart disease is well known, and also that cardiovascular disease are the leading cause of death in Western societies $[7,8]$.

According to statistics in the United States of America, hypertension is present in $69 \%$ of patients with acute myocardial infarction, $77 \%$ of patients with stroke and $74 \%$ in those who develop heart failure. It is the main risk factor for the development of renal failure, atrial fibrillation and diabetes mellitus.

Clinically it is estimated as the diastolic tension plus one third of the PP (Pulse Pressure), although in high cardiac frequencies it approaches more to the arithmetic average of the SAD and TAD. It is important to remember that the pulsatile component of blood pressure is represented by PP, which is affected fundamentally by three factors:

- The systolic volume of the heart

- The capacity of the arterial tree

- The reflections of the waves

PAm is determined by cardiac output multiplied by total peripheral resistance [9]. These variables are subject to constant change and are influenced by each other.

Central artery rigidity and systolic pressure are major determinants of cardiovascular risk in the elderly, while increased systemic vascular resistance and diastolic pressure predominate in young patients. There is evidence that the magnitude of the AT increases with the altitude level and with the degree of exercise and can be reversed after prolonged residence at sea level [10].

Measurements of blood pressure were made in a sample of 8,352 adults aged 20 years or older. Adults who had complete blood pressure data and those who reported having previously received a diagnosis of hypertension were included in the analysis. With a final sample of 054 subjects representing 8 to 67.8 million adults aged 20 years or more. In both surveys the same protocol and recommended by the American Heart Association procedures was used.

The classification used to categorize blood pressure was described in the Joint National Report for the Diagnosis of Hypertension (JNC 8). Because for measuring blood pressure in ENSANUT MC 2016 it was used digital sphygmomanometer and Omron HEM-907 XL was used and ENSANUT 2012 sphygmomanometer mercury was used, the prevalence of hypertension is not comparable.

The prevalence of hypertension of 2012 ENSANUT had a sensitivity of $74.9 \%$ and specificity of $92.2 \%$. To make the adjustment, the results of a subsample of ENSANUT 2012 ( $n=3,670$ adults) were used, which was measuring blood pressure using both the Omron digital sphygmomanometer and the mercury baumanometer. Should be considered in the adjusted ENSANUT 2012 defined by finding hypertension, and therefore these prevalences differ from those reported in publications prevalences where no adjustment made [11].

Currently, JNC8 recommends starting treatment with a blood pressure of 150/90 mmHg in adults over 60 years old. Recommending the pharmacological treatment of hypertension in adults over 60 years of age if their systolic blood pressure is greater than $150 \mathrm{mmHg}$ or diastolic greater than $90 \mathrm{mmHg}$.

As for the recommended antihypertensive drug, treatment with thiazide diuretics, calcium antagonists, angiotensin converting enzyme inhibitors (ACEI), or angiotensin II receptor antagonists (ARA) may be initiated for the general non-black population II). For black patients, the recommended starting drugs are either thiazide diuretics or calcium antagonists. If the patient has chronic kidney disease, the recommended drugs are ACE inhibitors or ARBs [12].

Being the main objective of antihypertensive treatment is the maintenance of the BP figures previously mentioned. If objectives are not reached within a month, it is recommended to increase the dose of the drug used or to add a new one (this last option has to be evaluated if the BP figures at the beginning are greater than $160 / 100 \mathrm{mmHg}$ ). In general, it is recommended not to use the association ACEI / ARA II. Finally, if we do not reach the targets if we add a total of 3 drugs, the recommendation is to refer to a unit specialized in hypertension [13].

An analysis shows that, in 2010, the direct costs for HTA care were just over 2,446 million dollars and they went to 3,100 million in 2012 . As indirect costs increased in those same dates of more than 2,713 millions of dollars to more than 3,437 million.

The objective of this study was to determine the spectra of the presentation of blood pressure types in elderly hypertensive patients participating in the San Luis Potosí Health, Welfare and Aging (SABE) survey.

\section{Materials and Methods}

Transversal study, an analysis was carried out on the data of people aged 60 years or older in the state of San Luis Potosí participating in the multicenter health and wellness and aging study [2].

The SABE study methodology was used to calculate the size of the sample of questionnaires to be applied, for each zone, $95 \%$ confidence interval parameters, a maximum allowed error of $+5 \%$ and a success rate to $50 \%$, as well as the population size corresponding to inhabitants of 60 years and over, according to the II Count of Population and Housing 2005 of the National Institute of Statistics and Geography.

The data were processed with the following formula to calculate the size of the finite population sample, based on proportions, considering a binomial distribution of the questionnaire, where the probability of success is in function of locating a person 60 years or older in a private dwelling. In this way we calculated the sample of our population to study thus taking 1823 records of the SABE survey corresponding to the year 2011-2012.

In addition, National Institute of statistics database of sea level elevation values of the municipalities of the State of San Luis Potosí was consulted using a geographic information system with which based on the information of the Continuous of Mexican Elevations and with the polygons of the urban and rural localities of the National Geostatistical Framework.

This analysis as a research project once the research project was designed was sent to SIRELCIS to be evaluated, approved and with Registration Authorization Committee for Ethics and Research: R-2015-2402-11.

The Health Welfare Aging survey (SABE San Luis Potosí): consists of a questionnaire consisting of 11 sections, which in total add up to 486 items, plus a section of identification data, as well as a section of questions and final comments. The survey was carried out across the state, both in urban and rural areas, including areas where the indigenous population is located.

Their study variable were men and women older than 60 years old, who live in the state of San Luis Potosí, randomly selected by clusters, the sample was calculated based on proportions. Field personnel were 
Page 3 of 4

selected and trained by the Autonomous University of San Luis Potosí. After 8 weeks of field work, 2,320 questionnaires were applied in a total of 260 localities, including the 58 municipal headwaters of the state.

Once the information was collected, a database was carried out in the Excel program, including only the variables of interest (previously selected from the SABE survey), of which for the present analysis the information of the elderly was used. At rest, the survey and determination of blood pressure were performed. The survey considered the fact that if the older adult was known or not with high blood pressure. It should be noted that the personal data of the participants was kept confidential.

To obtain the parameters, a binaural stethoscope and a baumanometer with an adult bracelet were used. Two measurements were taken with two minutes interval to obtain the average. Blood pressure values were determined according to NOM-030-SSA2-2009, for the prevention, detection, diagnosis, treatment and control of systemic arterial hypertension. For the analysis of frequency distributions of variables we used measures of central tendency, percentages, averages and standard deviation.

\section{Results}

We included 1823 (55.8\%) women and (44.2\%) men whose average age was $71 \pm 8.2$ years, of which $781(42.8 \%)$ had high blood pressure and their average age was $72 \pm 8.3$ years. The most frequent chronic diseases were hypertension (42\%) and diabetes mellitus (43\%) and each one was associated with different diseases such as heart failure, cardiovascular disease, cerebral vascular disease, chronic obstructive pulmonary disease and smoking.

Mean systolic blood pressure was $130 \mathrm{mmHg}$ in the general population, $143 \mathrm{mmHg}$ in hypertensive patients, $135 \mathrm{mmHg}$ in diabetics, while diastolic blood pressure was $80 \mathrm{mmHg}$ in the general population, $88 \mathrm{mmHg}$ in hypertensive patients, $89 \mathrm{mmHg}$ in diabetics, mean body mass index (BMI) in hypertensive patients was $26.9 \mathrm{~kg} / \mathrm{m}^{2}$, cardiovascular disease was present in $6 \%$ of the general population and in $7 \%$ of hypertensive while in diabetics in $10 \%$, cerebrovascular event had occurred in $2.9 \%$ in the general population, $3.8 \%$ in hypertensive individuals and in $5.2 \%$ in diabetics (Table 1 ).

\begin{tabular}{|c|c|c|c|c|c|c|c|}
\hline & $\begin{array}{c}\text { General } \\
\text { Populatio } \\
n\end{array}$ & $\begin{array}{c}\text { Hypertensio } \\
n\end{array}$ & Men & $\begin{array}{c}\text { Woma } \\
\mathrm{n}\end{array}$ & $\begin{array}{l}\text { Diabeti } \\
\text { c }\end{array}$ & $\begin{array}{l}\text { Less } \\
\text { than } \\
80\end{array}$ & $\begin{array}{c}\text { More } \\
\text { than } \\
80\end{array}$ \\
\hline $\mathrm{N}$ & 1823 & 781 & 805 & 1018 & 793 & 1475 & 349 \\
\hline AGE & $71 \pm 82$ & $72 \pm 8.3$ & $\begin{array}{c}72.3 \pm \\
8.1\end{array}$ & $\begin{array}{c}71.4 \pm \\
8.3\end{array}$ & $\begin{array}{c}71.8 \pm \\
8.1\end{array}$ & $\begin{array}{c}68.8 \pm \\
5.7\end{array}$ & $\begin{array}{c}84.5 \pm \\
4.3\end{array}$ \\
\hline TAS & $\begin{array}{c}130.6 \pm \\
17.9\end{array}$ & $\begin{array}{c}143.8 \pm \\
17.7\end{array}$ & $\begin{array}{r}129.2 \\
\pm 17.8\end{array}$ & $\begin{array}{r}131.6 \\
\pm 17.9\end{array}$ & $\begin{array}{c}135 \pm \\
18.8\end{array}$ & $\begin{array}{r}130.6 \\
\pm 17.6\end{array}$ & $\begin{array}{r}130.4 \\
\pm 19.1\end{array}$ \\
\hline TAD & $80 \pm 13.0$ & $88.6 \pm 13.6$ & $\begin{array}{c}80.2 \pm \\
12.8\end{array}$ & $\begin{array}{c}80.6 \pm \\
13.1\end{array}$ & $\begin{array}{l}8.9 \pm \\
13.9\end{array}$ & $\begin{array}{c}80.5 \pm \\
12.6\end{array}$ & $\begin{array}{c}79.9 \pm \\
14.3\end{array}$ \\
\hline PAM & $113 \pm 141$ & $\begin{array}{c}125.4 \pm \\
12.2\end{array}$ & $\begin{array}{l}112.9 \\
\pm 142\end{array}$ & $\begin{array}{r}114.6 \\
\pm 13.9\end{array}$ & $\begin{array}{c}117.3 \pm \\
14.3\end{array}$ & $\begin{array}{r}113.9 \\
\pm 13.8\end{array}$ & $\begin{array}{r}113.6 \\
\pm 15.1\end{array}$ \\
\hline BMI & $\begin{array}{c}26.1 \pm \\
4.9\end{array}$ & $26.9 \pm 4.9$ & $\begin{array}{c}25.3 \pm \\
40.3\end{array}$ & $\begin{array}{c}26.7 \pm \\
5.2\end{array}$ & $\begin{array}{c}27.5 \pm \\
5.0\end{array}$ & $\begin{array}{c}26.5 \pm \\
4.8\end{array}$ & $\begin{array}{c}24.2 \pm \\
4.7\end{array}$ \\
\hline ICC & $942 \pm 0.7$ & $942 \pm 0.76$ & $\begin{array}{l}0.942 \\
\pm 0.7\end{array}$ & $\begin{array}{c}941 \pm \\
0.7\end{array}$ & $\begin{array}{l}0.943 \\
\pm 0.7\end{array}$ & $\begin{array}{l}0.942 \\
\pm 0.7\end{array}$ & $\begin{array}{l}0.942 \\
\pm 0.7\end{array}$ \\
\hline $\begin{array}{l}\text { SMOKI } \\
\text { NG }\end{array}$ & $9.80 \%$ & $9.00 \%$ & $\begin{array}{c}17.40 \\
\%\end{array}$ & $3.80 \%$ & $5.80 \%$ & $\begin{array}{c}10.40 \\
\%\end{array}$ & $7.40 \%$ \\
\hline
\end{tabular}

\begin{tabular}{|c|c|c|c|c|c|c|c|}
\hline $\begin{array}{c}\text { CV } \\
\text { DISEAS }\end{array}$ & $6.00 \%$ & $7.00 \%$ & $4.10 \%$ & $7.50 \%$ & $10 \%$ & $5.20 \%$ & $9.20 \%$ \\
\hline
\end{tabular}

\section{Table 1: Overall results.}

It was found a direct relation of arterial hypertension in its different modalities with the appearance of cerebral vascular events, as well as to a higher BMI a greater number of elderly people with hypertension. Of all the patients with arterial hypertension, an analysis of the types of arterial hypertension was carried out, finding: Isolated systolic hypertension (35.7\%), Isolated diastolic hypertension (32\%) and Sistodiastolic hypertension (32.3\%) (Figure 1). With a higher percentage of isolated systolic hypertension in the group of adults from 70 to 79 years. But in adults over 80 the percentages between different types of hypertension are similar.

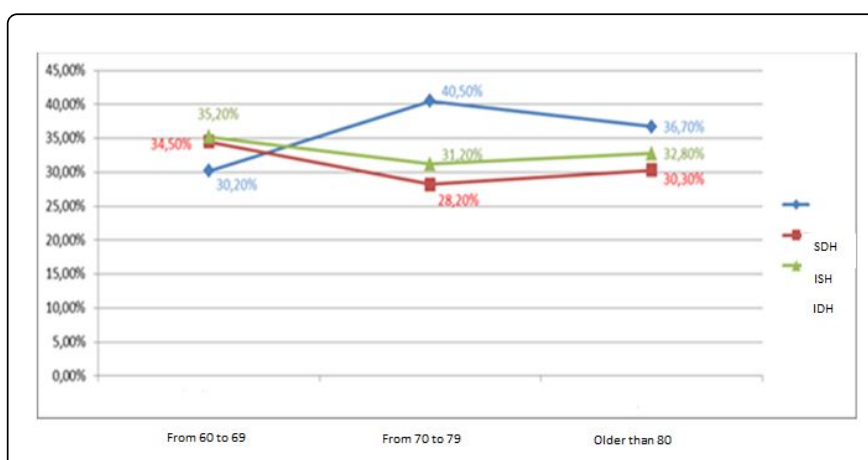

Figure 1: Prevalence by type of hypertension by age groups [systolic-diastolic hypertension (SDH), isolated systolic hypertension (ISH), isolated diastolic hypertension (IDH)].

\section{Discussion}

In comparison to the reported in the population of Peru and the population of San Luis Potosí by age group; from 60 to 69 years, a higher percentage of systolic-diastolic hypertension is observed, we found a percentage in the Mexican population of $35.2 \%$ compared to the Peruvian population of $40 \%$. Within the age group of over 80 years, there was an increase in cases of isolated systolic hypertension where $36.7 \%$ of the total population with this hypertension was observed [14].

According to the distribution by age group, it was possible to determine that there is a higher percentage of isolated systolic blood pressure between 70 and 79 years, which is similar to the findings reported by the Oviedo Group of Hypertension who found that in the age group between 68 and 82 years showed higher systolic blood pressure and pulse pressure [8].

An average mean arterial pressure of $60 \mathrm{mmHg}$ is necessary for an adequate perfusion in the different organs, however, being increased can be considered a cardiovascular risk factor. It was found to be higher in hypertensive and diabetic patients than in the general population, although hypertension in the older adult has a predominance of isolated systolic hypertension, we found that in the population the three types of hypertension have balanced percentages of almost one third each, with a very discrete predominance of the first, which has implications of great importance in the type of treatment of hypertension in the elderly. Since when considering the 
prevalences in thirds of the types of hypertension can be diagnosed early and given the appropriate treatment.

According to the gender in men has a more frequent systemic hypertension. A large percentage $(36.8 \%)$ of patients who were unknown with the diagnosis in whom isolated diastolic hypertension predominated were also found, which indicates the lack of early detection of this type of hypertension in the elderly, since most of hypertensive older adults in this group were asymptomatic. However, it is common to identify pathology by finding manifestations of chronic complications, developed from untreated hypertension.

High systolic and diastolic blood pressures may have different types of cardiovascular diseases and at different ages in a study of 1.25 million patients in primary care centers in England, new results suggest that individuals with higher systolic blood pressure present higher risk of intracerebral hemorrhage and stable angina while elevated diastolic blood pressure is a better indicator of the risk of abdominal aortic aneurysm [14].

In patients over the age of 60 the benefit of treating hypertension is well established in several trials. The British Society of Hypertension recommends to treat with antihypertensive drugs tensions values equal to or greater than $160 \mathrm{mmHg}$ of systolic and $90 \mathrm{mmHg}$ of diastolic.

\section{Conclusion}

This information is useful for screening campaigns and health policies in the field. However, for the blood pressure test, the variation with the different methods is a limiting factor. HT is a major global public health problem that is still growing. It is estimated that in Mexico there are more than 10 million subjects with arterial hypertension, in addition, which, each time with a larger population constituted of older age, which leads to an increase of arterial hypertension, since there is a direct relation with the age and with the different modalities of arterial hypertension with the appearance of cerebral vascular events, as well as to a higher BMI a greater number of elderly people with hypertension.

It is important to know that isolated systolic pressure is a phenomenon that is predominant in the elderly, however with a discrete difference between isolated diastolic arterial hypertension and systemic hypertension. The three modalities must be taken into account in order for the diagnosis and treatment to be performed effective and early.

The Framinghan study shows that the cardiovascular risk is even greater in the elderly than in the adult, and above all the isolated systolic HTA is in the elderly even more a clear risk factor than the diastolic. The clinical expression of hypertension as a risk factor in the elderly is mainly reflected in the higher incidence of acute stroke, ischemic heart disease and heart failure. The large international multicenter studies published in recent years have shown how normalization of blood pressure figures is followed by a decrease in cardiovascular events.

Calcium-antagonists are the drug of choice in geriatrics, acting to decrease peripheral resistance, without compromising circulation on the target organs or interfere with the most common associated pathologies in the elderly.

It is vital at the time of the consolidated purchase of antihypertensive drugs by health institutions to consider the prevalence of the 3 types of hypertension and to acquire for the three types of hypertension in this age group that have been mentioned, this will result in better therapeutic control avoiding the complications of this pathology.

\section{References}

1. National Institute of Statistics and Geography - Statistical Issues.

2. Welfare and Aging Health Survey SABE, San Luis Potosí. National Center for Preventive Programs and Disease Control (2012) ISBN: 978-607-460-329-3.

3. Rock F (2014) Approach to arterial hypertension in the elderly patient. SEMERGEN - Family Medicine 40: 3-9.

4. Herasa M, Fernández-Reyesa MJ, Guerrero (2014) Hypertension M.T. and cardiovascular risk. Hypertension Risk Vasc 31: 3-6.

5. Sierra C, López-Soto A, Coca A (2008) Hypertension in the elderly population. Rev Esp Geriatr Gerontol 43: 53-59.

6. Salazar Cáceres PM, Rotta Rotta A, Otiniano Costa F (2016) Hypertension in the elderly. Rev Med Hered 27: 60-66.

7. Poll Pineda JA, Rueda Macías NM, Poll Rueda A, Linares Despaigne MJ (2016) Atherogenic risk factors for hypertension in the elderly. MEDISAN 20: 978.

8. Villa Estébanez R, Tranche Iparraguirre S, Marín Iranzo R, Prieto Díaz MA, Hevia Rodríguez E (2002) Pulse pressure as a marker of cardiovascular risk in the elderly population. Aten Primaria 30: 374-380.

9. Carmona Puerta R, Acosta de Armas F, Perez de Armas A, Morales Salinas A, González Paz, et al. (2006) Arterial mean pressure and pulse pressure in young hypertensive patients. Med Clin (Barc) 127: 289-290.

10. Peñaloza D, Arias Stella J (2007) The heart and pulmonary circulation at high altitudes: healthy highlanders and chronic mountain sickness. Circulation 115: 1132-1146.

11. (2016) Half way survey.

12. Guideline based on evidence for the Management of AHT in Adults. Report of the members of the panel appointed member of the Eighth National Committee. Mixed (JNC 8) - 2014.

13. Regulo Agusti C (2006) Epidiology of arterial hypertension in Peru. Minutes Peruvian 23: 69-75.

14. Rapsomaniki E, Timmis A, George J, Pujades-Rodriguez M, Shah A, et al. (2014) Blood pressure and incidence of twelve cardiovascular diseases: lifetime risks, healthy life-years lost, and age-specific associations in 1.25 million people. The Lancet 383 (9932): 1899-1911. 